\section{Is the tide turning for Curieuse?}

'Curieuse tortoises on the way out?' (Oryx, 22, 4-5), illustrated the precarious situation of the introduced population of Aldabra giant tortoises Geochelone gigantea on Curieuse Island, Seychelles.

The Zoological Society of London expedition in 1986 detected problems that the tortoises and the Island as a whole are facing, and a conservation plan was drawn up to attempt to halt any further escalation of destruction. This plan has recently been approved by the Government of Seychelles and its main features include: the construction of a secure rearing unit for hatchling tortoises, an educational and conservation centre and the implementation of anti-poaching programmes.

In the educational centre it is planned to illustrate, through graphic displays, the ecology of both the Aldabra atoll and the Seychelles group, and to assemble a museum collection of the endemic flora and fauna. Another section of the graphic display will illustrate the importance of conservation in the Indian Ocean as a whole. Anti-poaching measures will include: adequate legislation governing visits to the Island, either by tourists or local residents; sign posting around the coastal plateaux stating the laws governing access; posters and leaflets at the main hotels and public places highlighting the conservation effort being undertaken; and additional personnel to help patrol the Island.

Curieuse was once described as 'the most barren and eroded Island in the Indian Ocean'. Several fires in the first half of this century destroyed most of the existing native vegetation. Today, thanks to the efforts of the Government, reforestation programmes have transformed most of its landscape, and much of its natural vegetation is flourishing. Some of the plants found on the Island are in the Red Data Book: Nephrosperma vanhoutteanum (Vulnerable), Deckenia nobilis (Vulnerable), Pandanus hornei (Indeterminate), Gastonia seychellarum (Endangered) and Toxocarpus schimperianus (Vulnerable). The Island and neighbouring Praslin are the only islands with wild Coco de Mer palms Lodoicea maldivica. Curieuse also has nine coastal plateaux, which are well-known nesting sites for the 240 hawksbill turtle Eretmochelys imbricata and the green turtle Chelonia mydas. There are also extensive coral reefs, rich in many species of flora and fauna, surrounding the Island. This, together with its terrestrial ecological features, makes Curieuse an extremely valuable natural resource.

The Zoological Society of London is seeking funds from concerned organizations and individuals to implement the proposed conservation plan and to help the Government of Seychelles in its efforts to preserve the Aldabra giant tortoise population and its unique environment on Curieuse Island. For further information, please contact: Mr Dave Spratt, The Zoological Society of London, Regent's Park, London NW1 4RY.

Jaime Samour PhD, Al-Areen Wildlife Park, PO Box 28690 , State of Bahrain.

\section{Ankarana damaged}

The Ankarana reserve in Northern Madagascar, which was described in the July issue of Oryx (22, 163-171), suffered serious damage from commercial logging earlier this year. Reports indicate that up to 30 per cent of the reserve's semi-deciduous canopy forest has been clear felled, the bulk of the damage occurring in the Canyon Grand area (P. Vaucolon, pers. comm.).

As described in Oryx these forests are home to a number of rare species. The white breasted mesite Mesitornis variegata (recorded from only two other localities), is especially threatened by the incursion. It was quite common in the Canyon Grand, but had a very limited distribution elsewhere in the reserve. Lemurs, including the aye-aye Daubentonia madagascariensis, crowned lemur Lemur coronatus and Sanford's lemur Lemur fulvus sanfordi are also threatened by the loss of these forests, which were an important dry season refuge.

Since the July article was written two more lemur species have been discovered at the reserve: the grey gentle lemur Hapalemur griseus and the Perrier's diadem sifaka Propithecus diadema perrieri, bringing the total to 10 extant species. The grey gentle lemur (which is possibly the subspecies H.g. occidentalis, recorded from just two other localities) was seen only in the Canyon

Oryx Vol 22 No 4, October 1988 
Grand and was apparently uncommon even there. The Perrier's diadem sifaka is recorded from one other locality to the east of Ankarana, and was seen at Ankarana in the dry forests to the north-east of the reserve, which were not disturbed in the recent felling.

The Ankarana incident is just the latest of a

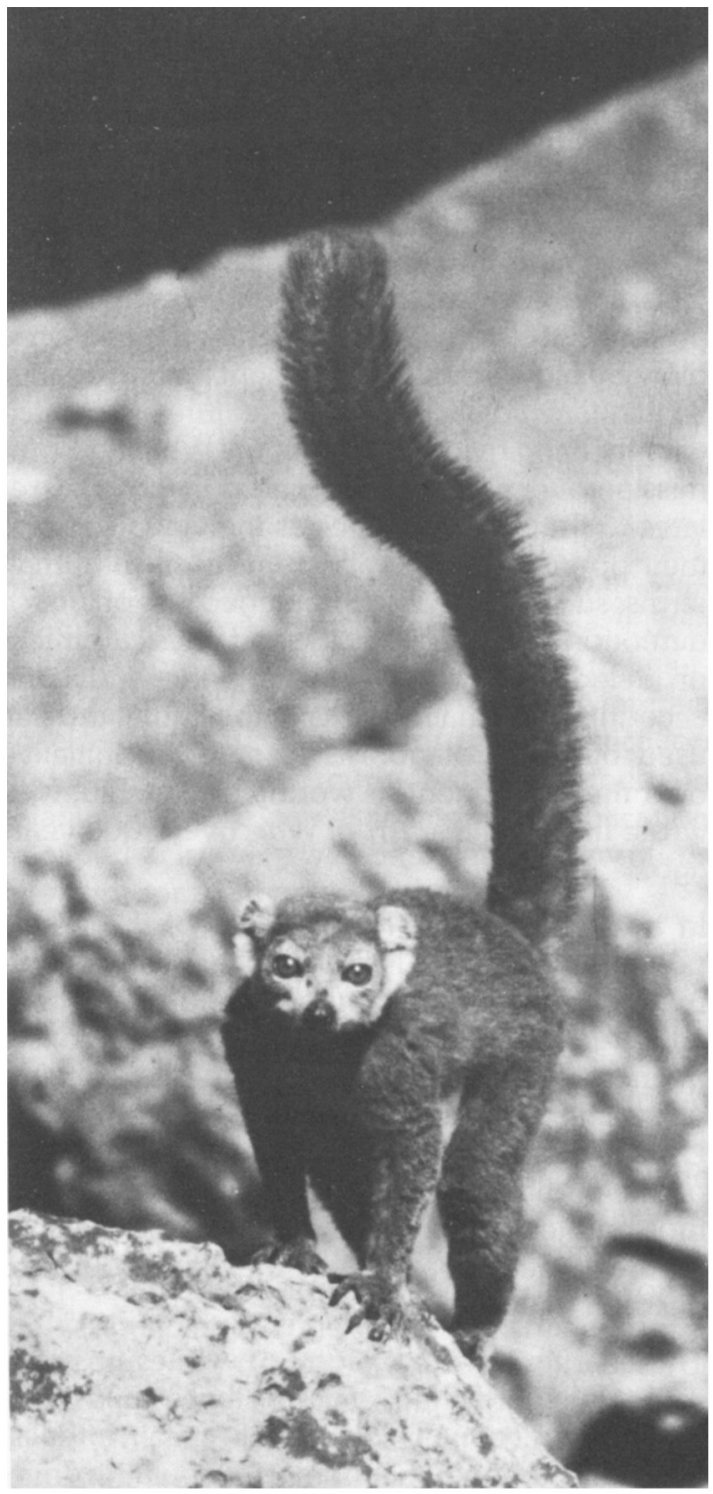

A female crowned lemur. This species, among others, is threatened by the destruction of forest at Ankarana (Jane Wilson). number of serious logging incursions into the tiny forest remnants of Northern Madagascar. Many endemics are threatened as a result.

Paul D. Stewart, Department of Biology, Southampton University, Southampton SO9 5NH, UK.

\section{The Indo-Chinese rhinoceros}

The last known surviving population of the threatened Javan rhinoceros Rhinoceros sondaicus lives in the Ujung Kulon National Park in Java. Several recent contributions about the wildlife of the Indo-Chinese countries (Vietnam, Laos, Kampuchea) presented evidence of the continued existence of a rhinoceros in that region, for example Thouless (1987) on some Kampuchean animals. He gave some data about the 'Javan rhino' surviving in Kampuchea, but in his discussion the rhinoceros remains unmentioned as a reason for special action.

The reason for uncertainty is doubt about the specific identity of the rhinoceros living in that part of the world. This is caused by a lack of data, an absence of museum specimens and by conflicting statements about the number of horns. In an earlier paper (Rookmaaker, 1980) I reviewed the available historical evidence about the rhinoceroses in the Indo-Chinese region. There were many uncertain records, but the few detailed ones all point to the Javan species only. One must always allow a measure of doubt, but in my mind I am convinced that the surviving specimens of rhinoceros in Laos, Kampuchea and Vietnam should be the Javan rhinoceros. The Sumatran rhinoceros Dicerorhinus sumatrensis could occur, but its presence has never been substantiated. It appears logical to work from the premise that all rhinoceroses living in the countries mentioned are Rhinoceros sondaicus only.

\section{References}

Rookmaaker, L.C. 1980. The distribution of the rhinoceros in Eastern India, Bangladesh, China and the Indo-Chinese region. Zoologische Anzeiger, 205, 253-268.

Thouless, C. 1987. Kampuchean wildlife-survival against the odds. Oryx, 21, 223-228.

L. C. Rookmaaker, Dokter Guepinlaan 23, $4032 \mathrm{NH} \mathrm{Om}$ meren, The Netherlands. 